\title{
PROCESSOS PARTICIPATIVOS E UNIVERSIDADE. BALANÇO DE UMA EXPERIÊNCIA EM DISCIPLINA DE PAISAGISMO
}

\author{
LIMA, Catharina \\ Doutora em Arquitetura e Urbanismo pela FAUSUUP; Professora Doutora da FAUUSP. \\ E-mail: Ga2001@uol.com.br

\section{QUEIROGA, Eugenio Fernandes} \\ Doutor em Arquitetura e Urbanismo pela FAUUSP; Professor Titular da FAU-PUC-Campinas; Professor do \\ Programa de Pós-Graduação em Urbanismo da PUC-Campinas; Professor Doutor da FAUUSP \\ E-mail: queiroga@usp.br
}

\section{GONÇALVES, Paulo Cássio}

Mestre em Arquitetura e Urbanismo pela FAUUSP; Professor de Arte e Multimídia do Colégio Santa Cruz E-mail:paulgon@uol.com.br

\section{RESUMO}

A participação da população na construção do espaço urbano é um direito inalienável da cidadania pelo qual também se mede o grau de democracia em uma sociedade. Garantida por leis e desejada pelos cidadãos, essas novas dinâmicas provocam mudanças nos processos de produção do espaço, demandando por sua vez novas posturas profissionais mais dialógicas e abertas ao novo e ao imprevisível. Essas novas realidades afetam diretamente a formação desse novo arquiteto, que, para além da sua capacitação técnica, deverá compreender e responder às dinâmicas sócio-culturais de uma forma diferente, que incorpore a perspectiva da troca de saberes e longe de uma abordagem assistencialista ou demagógica. Esse texto traz o relato e discussão de uma experiência levada a efeito na disciplina optativa AUP 657 - Sistema de Espaços Livres, do Grupo de Disciplinas Paisagem e Ambiente da FAUUSP, em 2004 e conduzida pelos seus autores.

Palavras-chave: Processo participativo, experiência didática, ensino de paisagismo.

\begin{abstract}
People's participation in the construction of the urban space is an inalienable right of citizenship and it is also a measure through which democracy can be evaluated. These new dynamics, guaranteed by legislation and desired by citizens, provoke changes in space production processes that are more dialogical and opened to new and unexpected events. These new realities sure affect the graduation of this new architect, who, beyond technical capacitation, will have to learn and be responsive to social-cultural dynamics in a different way, one that encompasses the idea of the exchange of knowledge and is not demagogical. This text reports an experience carried out during the elective course AUP-657 - Open Space System, of the Landscape and Environment Group at FAUUSP,in 2004.
\end{abstract}

Key words: Participatory process, didactic experience, landscape design teaching.

\section{Introdução}

O tema da participação da sociedade nas dinâmicas de construção do espaço urbano, embora egresso dos movimentos sociais dos anos 1960, tem ganhado força no Brasil, sobretudo a partir do início do processo de redemocratização do país; neste sentido a promulgação da Constituição em 1988 se constituiu em um importante marco institucional. Por sua vez o Estatuto da Cidade, publicado em 2001, garante, como lei federal, o direito inalienável dos cidadãos participarem, 
em várias esferas, das decisões sobre o planejamento e gestão do território municipal e seu complexo de lugares, que afetam suas vidas, seu cotidiano.

É notório observar, por sua vez, a resposta da sociedade a essas "novas realidades" democráticas e pró-ativas, em processos que embora contraditórios e muitas vezes conflituosos, contribuem no balanço geral para a consolidação de uma nova cultura política onde o modelo estritamente representativo é questionado, para dar voz aos "representados", tradicionalmente silenciosos ou pouco ouvidos. Assim, é crescente o número de pessoas que manifestam o desejo de tomar parte das decisões que lhes dizem respeito e se organizam em grupos (formais ou informais), associações e organizações não governamentais, entre outros formatos, para reivindicar direitos sobre a cidade, lutando por equipamentos e projetos diversos nas áreas de educação, cultura, meio ambiente, lazer, habitação, saúde, segurança, etc.

Diante desse quadro, onde não apenas a população tem expressado a vontade de exercitar práticas cidadãs, mas, encontra amplo amparo legal para fazê-lo, é preciso refletir sobre posicionamentos e papéis dos técnicos envolvidos no planejamento e nos projetos do espaço urbano. No que nos diz respeito, mais especificamente, cabe o questionamento:

Em que medida os arquitetos estão preparados para fazer frente a essas novas realidades, para atuar de forma a incorporar efetivamente a participação do seu cliente - seja individual ou coletivo - no processo de projetar? De que forma escolas de arquitetura têm no país respondido a esses dinâmicas sociais em curso sem incorrer em proselitismos ou estratégias de marketing? No que diz respeito ao Ensino de Paisagismo em Escolas de Arquitetura (que tem feito opções desveladas e importantes pela promoção do espaço público), como incorporar, sem reducionismos e ao mesmo tempo de forma exeqüível, essa abordagem de projeto que abraça a complexidade e a dialética do espaço urbano? Quais os papéis (e o diferencial) da Universidade nesses processos? Qual a legitimidade e pertinência da sua atuação em processos que seguirão seu curso depois de realizadas as etapas de trabalho, sobretudo em regiões de extrema carência com relação aos projetos propostos?

Essas são algumas das várias questões que decorrem dessa forma diferenciadas de ver projeto como processo - um conceito que permeia as instâncias do planejamento, desenho e gestão - e que vê na participação da sociedade não apenas um direito fundamental da vida públi$\mathrm{ca}$, mas também um fator de enriquecimento criativo do trabalho do arquiteto e do arquiteto paisagista.

O Grupo de Disciplinas Paisagem e Ambiente (a exemplo de outras escolas de arquitetura no Brasil) tem levado a efeito alguns trabalhos, de caráter experimental e exploratório, tanto no âmbito do seu Curso de Graduação quanto de Pós-graduação. São trabalhos de ensino, pesquisa e extensão que muitas vezes promovem a fusão entre essas "gavetas", não raro estanques, da atividade acadêmica.

Neste artigo pretendemos discutir alguns dos aspectos aqui relacionados, tomando como referência a experiência realizada na disciplina optativa AUP 657 - Sistema de Espaços Livres, do Curso de Graduação da FAUUSP. Trata-se de um trabalho que, embora contenha muitas imperfeições, desenvolveu-se de maneira extremamente participativa, com alto grau de adesão e entusiasmo e com grande ganhos pedagógicos tanto para os alunos quanto para os professores e comunidade envolvida. No sentido mais legítimo de Paulo Freire (2004), para quem "ensinar não é transferir conhecimento, mas, criar as possibilidades para a sua própria produção ou a sua construção", buscamos nos desarmar com relação a perspectiva de um programa de disciplina fechado, garantido um processo onde a apresentação de conteúdos teóricos se entrelaçam a experiências de conhecimento do lugar, de ensaios propositivos em várias escalas, construídos coletivamente a partir do inter-câmbio entre a comunidade escolar do bairro e a Universidade. 


\section{Projeto de paisagismo participativo}

Iniciamos a organização da disciplina com reuniões para elaborar uma proposta de agenda para o curso, tínhamos como princípio trabalharmos em parceria com os educadores das escolas públicas de Pirituba, região da periferia norte da cidade de São Paulo, porque outros trabalhos já tinham sido realizados com eles.

Com o rascunho da agenda realizamos uma reunião com os educadores e eles propuseram uma saída para verificar as possibilidades de três locais para o projeto participativo de paisagismo. Decidimos, em concordância com os educadores, por uma área interna do bairro City Jaraguá, destinada inicialmente pelo CDHU para o lazer dos moradores do conjunto, mas o abandono propiciou a invasão por pequenos comerciantes.

O conjunto é um tecido urbano recentemente ocupado com construções que vão desde as várias tipologias de pequenos edifícios, projetos dos órgãos públicos responsáveis por habitação popular, até um conjunto residencial com gestão participativa e construção em mutirão que curiosamente repete o paradigma da adaptação cercada dos subúrbios norte americanos e transposta para a nossa elite na periferia rica da Grande São Paulo.

O acesso ao conjunto é pela estrada de Taipas, observando atentamente a ilustração que segue abaixo, fornecida pela Subprefeitura de Pirituba. Verificamos que a área tem três entradas, formando um bolsão. Em uma das nossas visitas, guiada pelas crianças e adolescentes moradores do Bairro, a nossa guia comentou que seu irmão fazia o monitoramento da área para os chefes do tráfico de drogas. A implantação do conjunto não está atenta à integração com o tecido urbano e com os outros conjuntos existentes e projetados, criando uma fragmentação e dificultando o trânsito entre os conjuntos.

Segundo o arquiteto Pierre Correia (2004), o conjunto ainda está em fase de implantação, passou por várias gestões e com isso sofreu muitas adaptações. A implantação das tipologias obedeceu à racionalidade de aproveitamento da topografia, não dispensando, porém, movimento de terras e desmonte do relevo original.

O projeto da Secretaria da Habitação e Desenvolvimento Urbano do Município de São Paulo (SEHAB) é de 1990 e previa a construção de 4.319 unidades habitacionais com população média prevista de vinte mil habitantes. A gestão do projeto é da SEHAB, mas a construção de maior parte das edificações foi de responsabilidade da Companhia Metropolitana de Habitação (COHAB).

Internamente as áreas livres públicas do bairro não são projetadas simultaneamente à implantação das unidades residenciais e resultam em fragmentos que normalmente dificultam a conexão com o restante do tecido e a sua apropriação para a utilização. Este fenômeno tem se repetido em muitos empreendimentos públicos do município de São Paulo.

As equipes técnicas de projeto de habitação popular ainda não conseguiram conceber o projeto da habitação em parceria com o da paisagem. O conceito de qualidade de morar parece ser produto para as classes dominantes, a concepção restritiva de projeto de habitação acaba produzindo estes vazios que são ignorados ou apropriados indevidamente, em detrimento do uso coletivo. Um dos resultados do processo em questão é a destinação da linha principal de drenagem do conjunto como área de lazer, sem haver até hoje ações que qualifiquem o local para o uso público.

A fragmentação do tecido urbano mostra-se, também, quando se separam bairros por muros, neste momento surgem adaptações dos usuários, que abrem passagens para 0 trânsito dos moradores. 


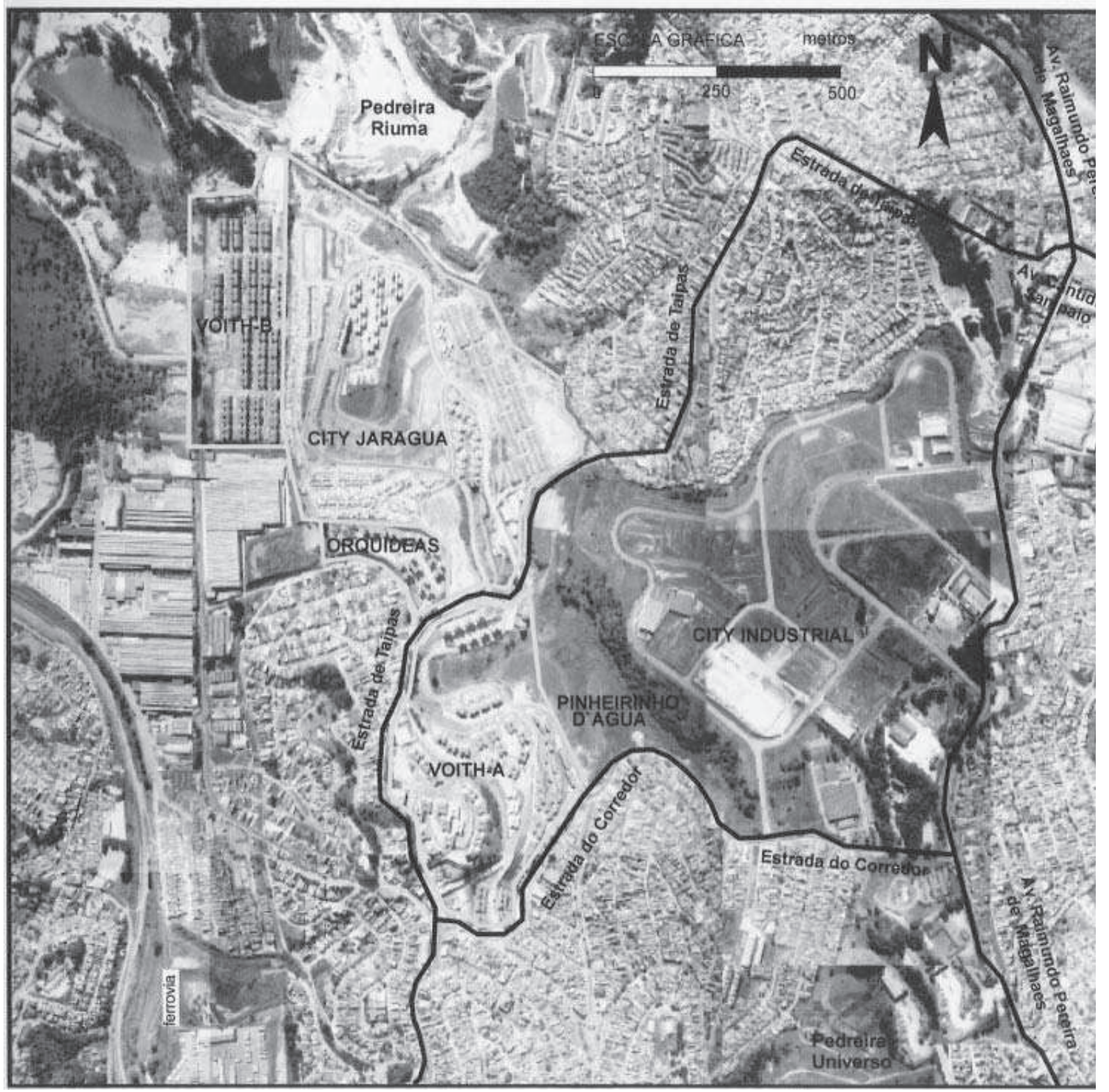

Mapa 1: O Conjunto Habitacional City Jaraguá

Fonte: Corrêa, 2004

A opção da área livre no Conjunto City Jaraguá implicou na necessidade de nos reunirmos com o maior número de educadores das escolas do entorno para a busca de parceiros. Estas reuniões foram nas escolas, essencialmente discutimos as possibilidades da participação das crianças e da participação dos pais e professores. Os professores apresentaram trabalhos executados os quais tinham temas ligados ao estudo da história do bairro e da análise da infra-estrutura existente. A produção era muito interessante, expressava eficientes diagnósticos das carências do bairro, no entanto, não havia a iniciativa de estimular os alunos à elaboração de propostas e de motivar os alunos a negociar suas sugestões com os representantes da administração pública. Através destas iniciativas foram produzidos registros da história da ocupação do bairro, da história dos personagens notórios do cotidiano, das condições do bairro. Avaliamos que a organização desta produção e a publicação em papel ou mídia eletrônica tornar-se-ia banco de dados que auxiliaria projetos pedagógicos e iniciativas de gestão participativa. Faltou-nos a percepção de que no início do processo poderíamos ter pedido aos participantes da comunidade escolar que apresentassem os trabalhos para a apreciação dos estudantes da graduação. 
Alguns professores das escolas não se sentiram à vontade na parceria com a Universidade e ou não conseguiram visualizar as possibilidades de trabalho, outros justificaram que o seu programa já estava decidido e não havia possibilidades de modificações para a parceria. Os coordenadores pedagógicos e educadores das Escolas Municipais Infantis (EMEI) propuseram algumas atividades internas e se prontificaram a enviar a produção de suas crianças para a Universidade.

Contamos com a ajuda de alguns professores da Escola Municipal de Ensino Fundamental José Kauffmann para recrutar crianças moradoras do bairro interessadas em participar das oficinas e da proposta de quatro projetos para o principal espaço livre do bairro.

Os representantes da universidade, o arquiteto da subprefeitura e os educadores envolvidos reuniram-se então para a negociação e acordo da agenda dos trabalhos e das responsabilidades de cada envolvido.

No início do semestre a disciplina teve uma procura significativa de alunos que mostraram-se motivados por duas características da disciplina: o trabalho com a participação da comunidade escolar do entorno e com o interesse da subprefeitura que acenava a possibilidade de destinar uma parte do orçamento para a execução de um projeto síntese das propostas discutidas pela população.

Mostramos aos alunos da graduação as experiências anteriores de projetos participativos trabalhados em disciplina de Pós-Graduação e propusemos inicialmente a apreensão do bairro em uma escala mais abrangente, um recorte na micro-bacia do Córrego Poço Grande. Buscou-se identificar o caráter da ocupação e visualizar as possibilidades da configuração de um sistema de espaços livres para considerações em um plano geral do bairro que repercutisse em soluções para a praça central do conjunto habitacional. Nesta escala seria necessário: localizar, categorizar e registrar em plantas os espaços livres públicos; compreender como se dá o mecanismo de drenagem da bacia e o processo ocorrido no desmonte da paisagem anterior e na construção de uma nova paisagem.

Nesta primeira etapa foram convidados diversos profissionais para aulas especiais na disciplina de graduação. O arquiteto Sílvio Martins da Subprefeitura de Pirituba apresentou o plano diretor regional de Pirituba Jaraguá, o arquiteto Pierre França Correa apresentou os resultados de suas pesquisas de mestrado no resgate da formação do bairro e da modelagem da paisagem, a arquiteta Zenilda Nogueira apresentou seu projeto de paisagismo para a área (elaborado a pedido da secretaria de habitação), a professora Márcia Rezende contribuiu com o relato do cotidiano dos processos pedagógicos participativos na área e o professor Paulo Romera que discorreu sobre o funcionamento da micro-bacia do Poço Grande.

Após as aulas e análises de dados oficiais inserimos na agenda uma visita para reconhecimento e registro de dados observados no perímetro da bacia com guias moradores e estudantes da EMEF Dr. José Kauffmann. No retorno do estudo de campo discutimos com os alunos o que eles observaram e requisitamos a representação gráfica de uma síntese das observações e das conclusões do grupo relacionadas à micro-bacia. Elaborou-se uma carta onde se buscou aferir as potencialidades de apropriação pública dos espaços livres, observando o caráter sistêmico de tais espaços e sua natureza "pervasiva" (LIMA). Neste sentido importou discutir não apenas a propriedade - pública ou privada - mas também as relações das diferentes esferas do cotidiano habitacional - privada, social e pública - e suas espacialidades - práticas espaciais - destacando-se aí, como categoria de análise do lugar, os processos de pracialidades - estados de praça - que se verificam em diferentes espaços, inclusive alguns edificados e de propriedade privada, mas de forte apropriação pública (QUEIROGA, 2004).

Para a segunda fase, o recorte era o conjunto habitacional. Foram convidados o arquiteto paisagista Caio Boucinhas (paisagista com experiências em processos participativos) e o professor Vladimir Bartalini (abordou a temática dos "córregos ocultos" da cidade). 

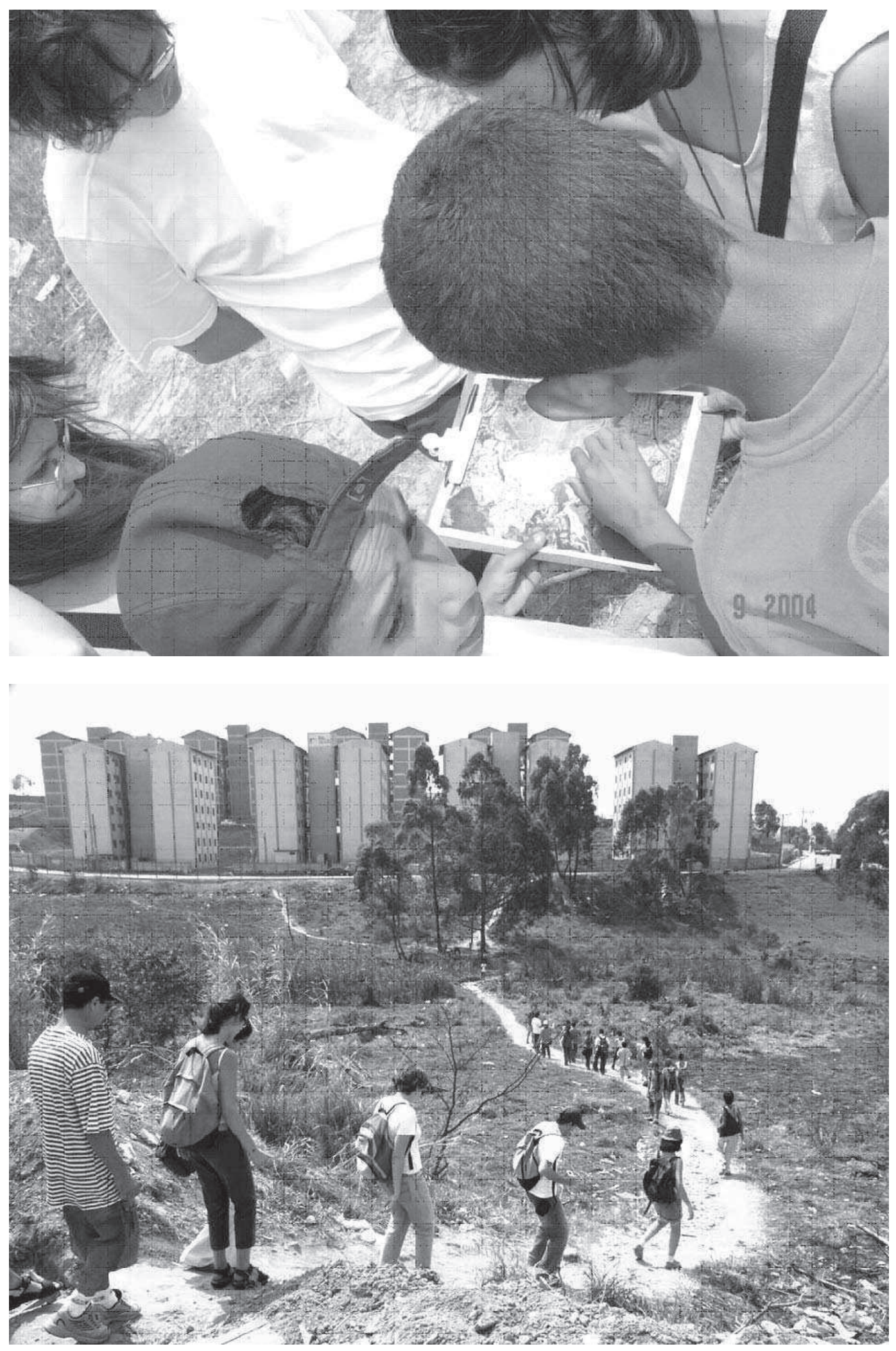

Fotos 1 e 2: Alunos do ensino fundamental guiando o grupo de alunos da graduação na visita à microbacia

Foto: Paulo Cássio Gonçalves

Providenciamos registros sobre a distribuição das tipologias das residências, da distribuição espacial e do uso das áreas livres públicas e a verificação de toda a infra-estrutura existente. O conjunto deveria ser analisado através do material fornecido pela subprefeitura e pela Se- 
cretaria da Habitação e somado às informações recolhidas na visita à área e nas oficinas com os moradores da área

Para facilitar este estudo, dada a extensão do conjunto, dividimos o bairro em oito áreas para que fossem visitadas por grupos de alunos da graduação guiados pelos alunos da EMEF José Kauffmann que residiam no local. A intenção era a de não apenas motivar o protagonismo juvenil, como também aprender com as crianças e adolescentes sobre seu cotidiano, seu universo de percepções, valores e desejos quanto ao seu bairro e arredores.

Os grupos saíram pelo bairro recolhendo informações através de entrevistas baseadas em questionário produzido pelos alunos, fotografias, desenhos e registro de descrições. Após três horas todos voltaram, e após um lanche discutiram os vários aspectos observados, os temas eram acompanhados de certo consenso entre os participantes somente a violência causou polêmica. Os moradores de uma das partes considerada violenta argumentaram na defesa de seu território, tentando provar aos demais que são exagerados os comentários sobre violência em seu "conjunto", apelidado de "Arábia Maldita".

Produzido rico diagnóstico das territorialidades existentes e das potencialidades de apropriação pública dos espaços livres do conjunto habitacional, as equipes de alunos da graduação realizaram uma proposta de diretrizes para o sistema de espaços livres do conjunto; base para que se iniciasse o projeto específico da praça central à luz de uma visão propositiva mais ampla.

No terceiro momento a proposta era trabalhar com a praça central do conjunto; os alunos elaboraram com as crianças participantes um mapa do uso cotidiano da área e um levantamento dos desejos de uso do local. Com estes dados esboçaram um diagnóstico específico do local de projeto.

Para esta fase foram convidados os arquitetos paisagistas Fany Galender, que discorreu sobre a "gramática dos projetos de paisagismo" e sobre o uso adequado da vegetação como elemento que pode estruturar os espaços e dar suporte a usos diversos, e o arquiteto Raul Pereira, que apresentou referenciais de seus projetos e dos diferentes processos de criação e das abordagens através da interpretação formal e simbólica dos espaços.

Os alunos de graduação requisitaram mais uma visita para resolver algumas dúvidas de dados oficiais conflitantes. Os participantes da comunidade escolar compareceram e foram apresentados a eles os esboços dos alunos de graduação para a área da praça. Fomos para a nascente existente na área e discutimos as potencialidades do sítio. Neste encontro ficou muito evidente o vínculo estabelecido entre os alunos da graduação e as crianças moradoras que participaram do projeto.

Com todos os dados e discussões chegou o momento de imersão no projeto, montamos uma exposição com os desenhos enviados pelas escolas de educação infantil no ateliê e estimulamos alguns dos alunos a apreciar e especular sobre os desejos representados pelas crianças de três a seis anos.

Por diversas razões as atividades propostas pelos professores das escolas infantis não foram acompanhadas por nenhum dos professores e dos assistentes, a impossibilidade de estar presente no cotidiano pode ser suprida quando decidirmos procedimentos que possibilitem um registro objetivo das intenções das crianças em suas representações gráficas. Surgiu a necessidade de buscarmos referenciais e refletirmos sobre a produção das crianças nos projetos participativos e a otimização de sua contribuição.

Convidamos os alunos, familiares e professores do conjunto City para um encontro na faculdade para a apresentação das propostas dos grupos. $O$ edifício da Faculdade de Arquitetura da Universidade de São Paulo incitou a curiosidade dos nossos parceiros e fizemos uma visita guiada com eles, como uma retribuição ao seu esforço como nossos guias em seu bairro. 
Para iniciar a assembléia apresentamos nossos registros do processo, resgatando todas as atividades realizadas até aquele momento. Feito isso, os grupos de alunos apresentaram suas propostas através de maquete e desenhos. A assistência portou-se um pouco tímida e formal durante a maior parte das apresentações, com poucas perguntas, mas com uma concentração impar. Após as apresentações pedimos aos grupos que fixassem todos os desenhos para que os convidados pudessem apreciar, questionar e propor. Esquecemos de formalizar para os alunos da graduação a necessidade de anexar o registro desta participação.

Finalizado o ano letivo, iniciado o seguinte, os educadores do bairro e o representante da subprefeitura voltaram a procurar a Faculdade para apresentarmos as propostas dos grupos e auxiliar no processo de revisão e síntese das propostas. Participamos de algumas reuniões para a discussão das possibilidades e para pontuar os limites da participação da universidade.

A faculdade não tem ainda a cultura deste tipo de trabalhos, esta experiência soma-se a anteriores para indicar as necessidades estruturais e para esclarecer os limites da atuação dos trabalhos da universidade.

Os projetos participativos com comunidades escolares estimulam a saída de alunos e professores para a observação do entorno e a elaboração de diagnósticos. Este olhar para o tecido urbano próximo a escola proporciona um grande envolvimento dos alunos, animados por reconhecerem o objeto de estudo e por este ser carregado de significados. Acreditamos que o envolvimento da escola na concepção de espaços e na possibilidade de dialogar com os representantes do poder local e da administração pública forma cidadãos conscientes de suas possibilidades de participação. Para os educadores da rede pública a experiência apresentouse como um desafio e exigiu um envolvimento com as questões apresentadas pelos integrantes da comunidade escolar.

Para algumas das lideranças locais parece ter se apresentado como uma possibilidade de mobilização para negociação sem a necessidade de vinculação a uma estrutura partidária. Para alguns políticos locais que ainda não conseguiram assimilar e beneficiar-se com este modelo de trabalho o projeto participativo pode soar como uma ameaça, já que os participantes experimentam (em graus diferentes) a sensação de poder participar da administração da cidade.

A experiência para os alunos da graduação apresentou-se como uma oportunidade de um primeiro trabalho com clientes reais, com demandas emergenciais e com a prontidão para discutir as análises e soluções dos estudantes para seu bairro.

Para o arquiteto da prefeitura e para os professores e pesquisadores da pós graduação da universidade foi uma experiência impar porque exige a organização de um método dialógico de pesquisa e projeto, intermediar negociações constantes entre os diversos atores e ler criticamente todos os fatos e iniciativas.

\section{Algumas palavras sobre os papéis da universidade}

Experiências como esta aqui relatada têm sido cada vez mais freqüentes no âmbito das escolas de arquitetura no Brasil. No que diz respeito à participação da universidade, é evidente que todas são louváveis, na medida em que propiciam aos alunos um maior contato com as dinâmicas sociais urbanas e promovem algum nível de troca de experiências, além de,em muitos casos,culminar com a própria implantação de um projeto.

96 Tudo isso é muito rico, mas, nesse balanço final sobre a experiência relatada, cabem as perguntas: qual o papel diferenciado da universidade nessas iniciativas? $\bigcirc$ que ela acrescentaria ao processo? Em que se distinguiria de um escritório de consultoria contratado, por exemplo, pelo poder público para o mesmo fim? 
O exercício de sua capacidade crítica, preservando a todo custo sua autonomia, é um primeiro diferencial; todos esses processos devem ser objeto de contínuas avaliações, entendendo essa autocrítica honesta como uma condição fundamental para a evolução das idéias. Nesse sentido é importante que fique claro para todos os participantes que, ainda que envolva projeto e o tempo inteiro um senso de viabilidade, caracterizando-se muitas vezes como trabalhos de extensão,não se trata de uma "encomenda" e sim,fundamentalmente, de um processo de compartilhamento de saberes e percepções;assim, constituindo-se uma experiência pedagógica, deverá estar aberta à crítica e alterações no percurso. Boaventura Santos (1995) define bem essa característica quando diz que "a universidade é talvez a única instituição nas sociedades contemporâneas que pode pensar até as raízes as razões por que não pode agir em conformidade com seu pensamento. É este excesso de lucidez que coloca a universidade numa posição privilegiada para criar e fazer proliferar comunidades interpretativas," um excesso de lucidez que não se pode permitir fugir a uma prática de avaliação contínua e profunda,analisando criticamente seus papéis, pertinências, motivações e procedimentos.

Um outro aspecto não menos importante é o de que o balanço dessa crítica deve estar atrelado à produção de conhecimento, gerando pesquisas e outros trabalhos, contribuindo para o desenvolvimento do estado da arte da literatura sobre o assunto. Este, igualmente, constitui-se um outro diferencial da atuação de uma universidade nas práticas sociais do seu tempo. Uma experiência didática participativa, por mais que tenha ganhos pedagógicos inequívocos, resulta endêmica se não puder ser disseminada, estimulando reflexões que transcendam, em um primeiro momento, o plano eminentemente empírico, para depois ser capaz de criar ciclos de retroalimentação que dêem suporte teórico à experiência prática.

Em tempo, os desafios desse novo século pedem novas posturas e atitudes profissionais, exigindo que sejam repensadas as práticas didáticas que balizam a formação desse novo arquiteto, urbanista, paisagista, dentro de uma perspectiva de auto-avaliação contínua.

\section{Bibliografia}

ABRAMOVAY, Miriam. Escolas inovadoras: Experiências bem sucedidas em escolas públicas. Brasília: Unesco, 2003.

ABRAMOVAY, Miriam; RUA, Maria das Graças. Violências nas escolas. Brasília: Unesco, 2002.

ADAMS, Eilen; INGHAM, Sue. Changing places: Children's participation in environmental planning. Londres: Planning aid of London and the children's society, 1998.

ASSOCIAÇÃO INTERNACIONAL DAS CIDADES EDUCADORAS. Disponível em: <http://www.bcnweb13.bcn.es:81/ NASApp/eduportal/pubPortadaAc.do>.

BORDENAVE, Juan E. Diaz. O que é participação. São Paulo, 1994.

BRASIL. Constituição da República Federativa do Brasil. 19. ed. São Paulo: Saraiva, 1998.

CÂMARA MUNICIPAL DE SÃO PAULO - São Paulo. Plano Diretor: Cartilha de formação. São Paulo: Caixa Econômica Federal, 2003.

COMERIO, Mary C. Community design: Idealism and entrepreneurship. In: SANOFF, Henry. Participatory design: Theory and techniques. Raleigh, 1990.

CORRÊA, Pierre França. Paisagem e sentido de lugar: Uma abordagem para os espaços livres em conjuntos habitacionais. 2004. Dissertação (Mestrado) - Faculdade de Arquitetura e Urbanismo, Universidade de São Paulo, São Paulo, 2004.

DIETRICH, Schiel; MASCARENHAS, Sérgio. O estudo de bacias hidrográficas, uma estratégia para educação ambiental. São Carlos: RIMA, 2002.

FREIRE, Paulo. Uma educação para a liberdade. Porto: Textos Marginais, 1974.

Pedagogia da autonomia - Saberes necessários à prática educativa. São Paulo: Paz e Terra, 2004. 
GADOTTI, Moacir; PADILHA, Paulo Roberto; CABEZUDO, Alicia (Orgs.). Cidade educadora. São Paulo: Cortez, 2004.

GOVERNO FEDERAL. Estatuto da Cidade, Lei Federal n. 10.257, de 10 de julho de 2001.

LEITE, M. A. F. P. A produção e o uso da paisagem metropolitana - Indicação da disciplina.

LIMA, Mayumi Sousa. A cidade e a criança. São Paulo: Nobel, 1989.

Arquitetura e educação. São Paulo: Studio Nobel, 1995.

MARTINS, Maria Lucia Refinetti. São Paulo: Além do Plano Diretor. Estudos Avançados, v. 47, n. 17, São Paulo, 2003.

MOORE, Robin C; WONG, Herb H. Natural learning: The life history of an environement schoolyard. 2. ed. Berkeley: UC, 1997.

PREFEITURA DE SÃO PAULO. Disponível em: <http://www.portal.prefeitura.sp.gov.br/cidadania/conselhosecoordenadorias/cpp/politicaspublicas $>$.

PREFEITURA DE SÃO PAULO, Secretaria Municipal de Educação e Diretoria de Orientação Técnica. Educação para a democracia, direitos humanos e cultura da paz: Um desafio pedagógico na cidade educadora. São Paulo: PMSP, 2003.

PONTUSCHKA, Nídia Nacib. Um projeto... tantas visões, educação ambiental na escola pública. São Paulo: Faculdade de Educação da Universidade de São Paulo, 1996.

O conceito de estudo do meio transforma-se em tempos diferentes, em escolas diferentes, com professores diferentes. São Paulo: Papirus.

PONTUSCHKA, Nídia Nacib; VESENTINI, José Willian (Org.). O ensino de geografia no século XXI. 1 ed. São Paulo: Papirus, 2004.

QUEIROGA, Eugenio. Entre a megalópole e a praça: Notas dialéticas sobre paisagens urbanas contemporâneas e possibilidades projetuais do espaço público. In: VII ENCONTRO NACIONAL DE ENSINO DE PAISAGISMO EM ESCO. LAS DE ARQUITETURA E URBANISMO, 2004, Belo Horizonte. Anais... Belo Horizonte: UFMG, 2004. (CD-ROM)

SANOFF, Henry. Participatory design: Theory \& techiniques. Carolina do Norte: North Carolina State University, 1990.

A visioning process for designing responsive schools. Carolina do Norte: National Clearinghouse for Educational Facilities, 2001.

SANTOS, Boaventura. Pela mão de Alice - O social e o politico na pós-modernidade. São Paulo: Cortez Editora, 1995.

SEMLER, Ricardo; DIMENSTEIN, Gilberto; GOMES DA COSTA, Antonio Carlos. Escola sem sala de aula. Campinas: Papirus, 2004.

SINGER, Helena. República das crianças, uma investigação sobre as experiências escolares de resitência. São Paulo: Hucitec/Fapesp, 1997.

SPIRN, Ann W. O Jardim de granito. São Paulo: Edusp, 1995.

VAINER, Carlos Bernardo. As escalas do poder e o poder das escalas: O que pode o poder local? In: IX ENCONTRO NACIONAL DA ANPUR: ÉTICA, PLANEJAMENTO E CONSTRUÇÃO DEMOCRÁTICA DO ESPAÇO, 2001, Rio de Janeiro. Anais... Rio de Janeiro, 2001. 